\title{
Design and testing of topology optimized heat sinks for a tablet
}

Martínez-Maradiaga, David ; Damonte, Alberto ; Manzo, Alessandro ; Haertel, Jan H. K.; Engelbrecht, Kurt

Published in:

International Journal of Heat and Mass Transfer

Link to article, DOI:

10.1016/j.ijheatmasstransfer.2019.07.079

Publication date:

2019

Document Version

Peer reviewed version

Link back to DTU Orbit

Citation $(A P A)$ :

Martínez-Maradiaga, D., Damonte, A., Manzo, A., Haertel, J. H. K., \& Engelbrecht, K. (2019). Design and testing of topology optimized heat sinks for a tablet. International Journal of Heat and Mass Transfer, 142, [118429]. https://doi.org/10.1016/j.ijheatmasstransfer.2019.07.079

\section{General rights}

Copyright and moral rights for the publications made accessible in the public portal are retained by the authors and/or other copyright owners and it is a condition of accessing publications that users recognise and abide by the legal requirements associated with these rights.

- Users may download and print one copy of any publication from the public portal for the purpose of private study or research.

- You may not further distribute the material or use it for any profit-making activity or commercial gain

- You may freely distribute the URL identifying the publication in the public portal 


\title{
Design and Testing of Topology Optimized Heat Sinks for a Tablet
}

\author{
David Martínez-Maradiaga, Alberto Damonte, Alessandro Manzo, Jan H.K. Haertel, Kurt \\ Engelbrecht ${ }^{*}$
}

Department of Energy Conversion and Storage, Technical University of Denmark, Roskilde, 4000 Denmark ( ${ }^{*}$ corresponding author, e-mail: kuen@dtu.dk)

\begin{abstract}
Thermal management is fundamental to ensure that electronics components operate at their design temperatures for improved performance and lifetime. As current electronic devices become more compact and more power dense, the amount of heat to be dissipated per area also increases. Therefore, it is necessary to design heat sinks capable of maintaining a low operating temperature and a small packaging envelope. Topology optimization, due to its geometric freedom, can be a useful tool to develop passive heat sinks capable of rejecting as much heat as possible in a limited space. This paper presents the design, modeling, and testing of topology optimized heat sinks for a commercial tablet. Firstly, a numerical model of the tablet's thermal behavior is developed. Secondly, the topology optimization problem is formulated and implemented. Two topology optimization approaches are used: the non-robust approach and the robust approach. COMSOL's optimization module is used to conduct the optimization and the Globally Convergent version of the Method of Moving Asymptotes is used as the optimization algorithm. Finally, three heat sinks were fabricated in aluminum: the two resulting topology optimized designs (robust and non-robust), and one baseline L-shaped heat sink. The latter heat sink is used to compare the performance of topology optimized and traditionally designed heat sinks. Both the numerical and experimental analysis showed that the non-robust heat sink performs the best. The non-robust heat sink is capable of reducing the average temperature of the tablet electronic components by approximately $3^{\circ} \mathrm{C}$ with respect to the baseline heat $\operatorname{sink}\left(48.5^{\circ} \mathrm{C}\right)$.
\end{abstract}

Keywords: experimental testing; heat sinks; modeling; topology optimization.

\section{Nomenclature}

$c_{p}(\mathrm{~J} / \mathrm{kgK}) \quad$ Specific heat capacity at constant pressure.

$C(A h) \quad$ Battery capacity.

$f \quad$ Objective function.

$h\left(\mathrm{~W} / \mathrm{m}^{2} \mathrm{~K}\right) \quad$ Convective heat transfer coefficient.

$I$ (mA) Average current supplied by the tablet battery.

$k(\mathrm{~W} / \mathrm{mK}) \quad$ Thermal conductivity.

$p \quad$ Penalization exponent.

$P(\mathrm{~W}) \quad$ Electric power.

$q\left(\mathrm{~W} / \mathrm{m}^{2}\right) \quad$ Heat flux.

$r \quad$ Filter parameter.

res Residual of the governing equations.

$Q$ (W) Thermal power.

$Q_{v}\left(\mathrm{~W} / \mathrm{m}^{3}\right) \quad$ Volumetric heat generation rate.

$t \quad$ Position shift parameter.

$T\left({ }^{\circ} \mathrm{C}\right) \quad$ Temperature.

$V_{\text {op }}(\mathrm{V}) \quad$ Operation voltage.

$\mathrm{Vol}\left(\mathrm{m}^{3}\right) \quad$ Total volume of the design domain.

X General variable. 


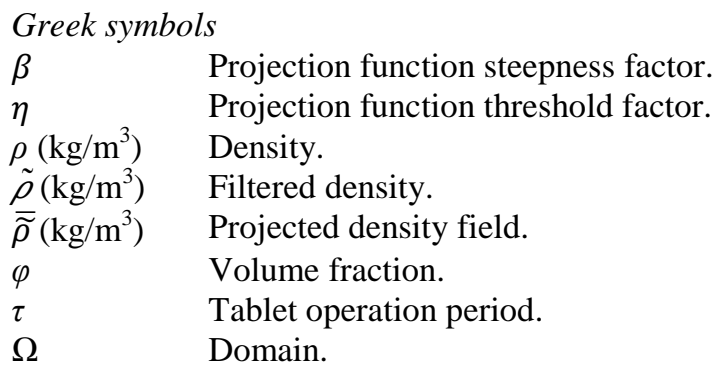

$\begin{array}{ll}\text { Acronyms } & \\ \text { CPU } & \text { Central processing unit. } \\ \text { GPU } & \text { Graphics processing unit. } \\ \text { IRC } & \text { Infrared camera. } \\ \text { LCD } & \text { Liquid-crystal display. } \\ P D S & \text { Power distribution system. } \\ R A M & \text { Random-access memory. } \\ \text { SoC } & \text { System-on-a-chip. }\end{array}$

\section{Introduction}

The trend in the electronics industry is to produce devices that are more compact while the performance and power requirements of these devices tend to also increase. As a result, more heat per area is generated, making it necessary to develop compact heat management solutions with high performance. Adequate thermal management of electronic devices is important because their operation and life can be compromised when they function at high temperatures or exhibit high-localized temperatures. For example, thermal stresses occur due to the differences in thermal expansion coefficients of the materials in printed circuit boards [1]. Another challenge of great importance for portable electronic devices is the temperature at the device surface. Current designs aim to limit maximum temperatures to between 40 and $45^{\circ} \mathrm{C}$ as well as to realize the highest possible temperature uniformity [2]. Berhe [3] conducted a survey with about 60 people in order to assess people's reactions to thermal comfort when holding test devices with different surface temperatures. The results showed that touch comfort depends on the enclosure material as well as the skin temperature of the device. The marginally acceptable skin temperature limits were $41^{\circ} \mathrm{C}$ and $45^{\circ} \mathrm{C}$ for the devices with an aluminum enclosure and a plastic enclosure, respectively.

Different technologies can be used to cool an electronic device. They can be passive (radiation and free convection) or active (forced convection or active cooling). Current research and development of these technologies are focused on: microchannels, heat pipes, heat pumps, spray cooling, phase change materials, free cooling, and thermoelectric cooling [4]. Heat sinks are one of the most used and cost-effective solutions for cooling electronic devices. They are found in many applications to transfer heat from a heat-generating component to its surroundings (or vice versa) by free or forced convection.

Traditionally, heat sinks have been designed based on trial and error approaches, experimental and numerical parametric studies, and the intuition of designers. In order to further enhance the performance of heat sinks, optimization studies can be conducted. These studies rely on analytical models or computational fluid dynamics models coupled with size and shape optimization approaches [5]-[7]. Such approaches are relatively easy to apply and straightforward; nevertheless, they are limited in the sense that a priori assumptions about the shape and configuration of the considered heat sink must be made, i.e. simple geometries such as plate fins, strip fins, pin fins, regular ribs are assumed. Bejan, in 1997, proposed an alternative approach for optimizing heat conduction point-to-volume problems based on constructal theory [8]. This method allows designing optimized high thermal conductivity paths by sequentially assembling blocks of a high conductivity material in order to minimize the maximum temperature of the domain. The amount of high conductivity material available as well as the total heat generation rate are fixed. As a result, tree-like configurations are obtained. Bornoff and Parry [9] proposed an additive design methodology based on constructal theory but applied to the design of a forced convection cooled heat sink. Recent studies apply constructal theory to other heat transfer problems such as convective heat transfer in nanofluid flow [10], microchannel network heat sinks [11], semi-elliptical morphing fins [12], etc. 
Another approach that allows optimizing the geometry of a given structure without prior assumptions about the shape or configuration of the final design is topology optimization [13]. Topology optimization was developed and matured in structural mechanics applications but has more recently been applied to a wide range of physics such as photonics, fluid mechanics, and heat transfer [14]. It aims at distributing material in a given volume, the design domain, in order to minimize an objective function subject to given design constraints. In density-based topology optimization, which is used in this work, the material distribution is represented by a design field which can take the value of 0 (void) or 1 (solid) in each point of the design domain. In the specific heat sink design problem considered in this work, 0 (void) corresponds to air and 1 (solid) corresponds to the heat conducting heat sink material. This binary optimization problem is relaxed to continuous values between 0 and 1 in order to allow for the use of efficient gradient-based optimization methods.

Topology optimization applied to problems in the context of thermal engineering such as heat sink and heat exchanger design is an active area of research [15]-[19]. First applications of topology optimization to heat transfer problems relied on 2D models that solve a thermal diffusion (heat conduction) problem where the heat transfer to the ambient fluid is represented by a heat transfer coefficient. Both models assuming a constant heat transfer coefficient [20], [21] and models using a surrogate model for the heat transfer coefficient $[16,22]$ are reported in the literature. More recent works apply complex 3D thermal diffusion models to heat sink design [23], and other technical applications [17, 24]. Thermofluid or conjugate heat transfer topology optimization models have been presented which explicitly capture the heat transfer in the ambient fluid during the optimization [25, 26]. This is done to overcome the limiting assumption of a constant heat transfer coefficient or a surrogate convection model. The design of forced convection heat sinks using thermofluid topology optimization models is presented e.g. in [19, 27]-[30]. Natural convection problems have only more recently been treated in the context of thermofluid topology optimization due to the strong coupling between the temperature and the fluid field. Alexandersen et al. pioneered this area and treated natural convection heat sink design problems using both 2D [31] and 3D [32] optimization models. Thermofluid topology optimization models are more complex than thermal diffusion models with assumed convection coefficient at the convective boundaries. Therefore, the former have significantly increased computational demand and numerical stability problems at higher Reynolds numbers. This latter issue has so far limited the vast majority of the works to laminar flow problems with low to moderate Reynolds numbers.

Even though there is a large body of literature on topology optimization applied to the design of thermal systems [33], only a few works have thus far addressed the fabrication and experimental validation of topology optimized designs for thermal applications. Koga et al. [28] experimentally validated a forced convection water-cooled microchannel heat sink that is designed using a thermofluid Stokes flow topology optimization. The additive manufacturing and experimental testing of an air-cooled heat sink designed using a thermal diffusion optimization model are presented in [23]. Soprani et al. [24] use a thermal diffusion model to optimize the thermal integration of a thermoelectric cooler into a robotic tool and subsequently fabricate and test an optimized prototype. In the work by Subramaniam et al. [18], a 2D thermal diffusion model with uniform heat generation and a prescribed temperature at one point of the boundary are used to generate optimized heat sinks which are fabricated and experimentally tested. Lei et al. [34] present fabrication using stereolithography-assisted investment casting and experimental validation of topology optimized natural convection heat sinks.

The topology optimization works mentioned above include experimental validation of optimized structures. All of them, except for [24], have in common that the heat sinks are designed in a more generic and academic context, without implementing them into a specific technical application. The aim of this work is to apply topology optimization to enhance the thermal management of a commercial tablet. In this device, the thermal load is located in three main electronic components: the system-on-a-Chip (SOC), the RAM, and the power distribution system (PDS). The heat generated by these electronic components is conducted to an aluminum shield, and is rejected to the plastic back cover of the tablet. In this paper, a thermal diffusion topology optimization model is used to design two heat sinks that minimize the average temperature of the aluminum shield. Furthermore, the topology-optimized heat sinks were manufactured and their performance was experimentally assessed by means of natural convection tests. 
(a)

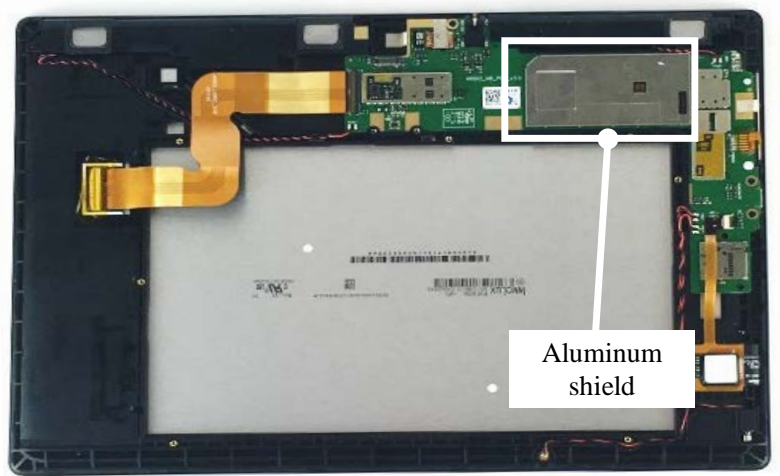

(b)

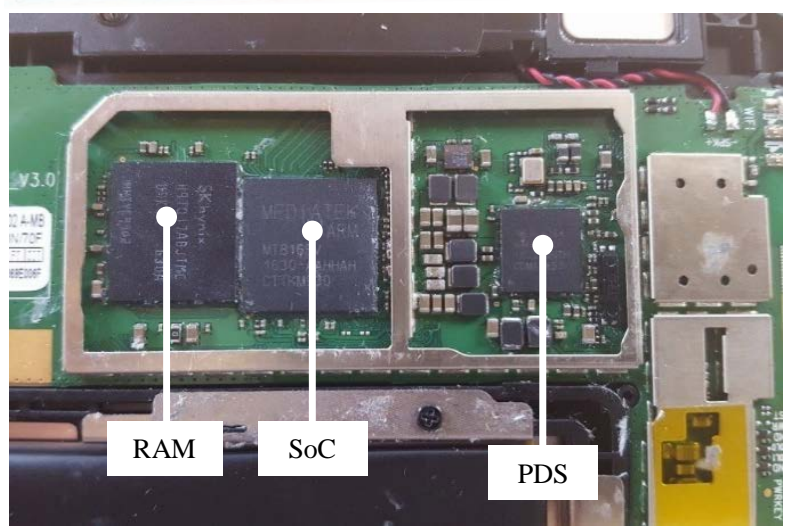

Figure 1. (a) Photograph of the tablet with the back cover removed and (b) detail of the components under the aluminum shield.

\section{Thermal modeling}

\subsection{Tablet components and operation}

The device studied in this work is a mid-range tablet. It has a 10.1 in LCD screen on the front and a plastic cover on the back. Figure 1a shows the tablet with the back cover removed. The main electronic components of the tablet are located under the aluminum shield. These components are the RAM, the SoC (that by definition includes the CPU, GPU and a memory controller), and the PDS (see Figure 1b).

In order to experimentally study the thermal behavior of the tablet, it is necessary to define a repeatable operation procedure. This operation procedure was designed to maximize the energy consumption of the processor, GPU and other major components as much as possible, and therefore, make it operate at its maximum temperature. The actions below were followed for each operation test:

- The screen was kept on with maximum brightness setting.

- The Bluetooth connection was turned on.

- The Wi-Fi connection was turned on.

- The GPS location was turned on and a navigation program was started.

- Several high power demand apps were run in the background to increase the stress on the RAM.

- The music player was turned on to use CPU power and increase the energy consumption of the speakers and their drivers.

- A video game that had a high CPU and GPU demand was played manually.

The process described above was carried out until the system reached steady state operation based on measured temperatures. This occurred after the tablet control system reduced the processor speed to prevent overheating of the system (see Fig 2). This testing procedure is repeatable from the standpoint that all experiments ran until the processor reached a critical temperature, with an estimated at an uncertainty of $1{ }^{\circ} \mathrm{C}$.

\subsection{Preliminary study of the tablet thermal behavior during operation}

A preliminary evaluation of the thermal behavior of the tablet was carried out by measuring the temperatures of the main electronic components and the aluminum shield. It is important to highlight that the 
tablet was always kept in the same position, $25^{\circ}$ with respect to a vertical plane, by means of a fixed holder for all experimental studies. Type- $\mathrm{K}$ thermocouples made from $0.25 \mathrm{~mm}$ wires were attached to the components and the aluminum shield. The thermocouples have an accuracy of $\pm 2.2^{\circ} \mathrm{C}$ and they were fixed by means of insulating tape. In addition, an infrared camera (IRC) was used to evaluate the temperature distribution during operation. The IRC is a Flir SC5000 IRC was used to study the temperature distribution in the tablet components during operation. The most relevant parameters of the camera are: focal lens, $27 \mathrm{~mm}$; temperature range, $5{ }^{\circ} \mathrm{C}-300{ }^{\circ} \mathrm{C}$; uncertainty, $+/-1{ }^{\circ} \mathrm{C}$ up to $100{ }^{\circ} \mathrm{C}$ and $+/-1 \%$ above $100{ }^{\circ} \mathrm{C}$. The IRC software, Altair, allows for post-processing of the recorded measurements in order to obtain time dependent temperature profiles for a selected group of pixels. In addition to uncertainty in the instruments, there is also uncertainty in the operation of the tablet. Since the system is controlled by proprietary software, the actual energy dissipation and distribution of electrical power within the tablet is uncertain. This can cause both local and temporal variations in temperature, increasing the overall uncertainty. Variations in the ambient temperature and air flow conditions can also affect temperature measurements reported here.

The continuous lines in Figure 2 show the temperature trends of the RAM and the SoC for 12 min of operation. It can be seen that the CPU has a temperature control system that prevents overheating of the unit: after 7 min of operation, the CPU temperature rises and falls cyclically keeping the temperature between approximately $82{ }^{\circ} \mathrm{C}$ and $98{ }^{\circ} \mathrm{C}$. These on-off cycles of SoC have an impact on the tablet performance in terms of slower, choppier operation. It can also be seen that the RAM temperature is lower than the SoC temperature and it follows a similar trend during the first $6 \mathrm{~min}$. Afterward, it stays nearly constant at $60{ }^{\circ} \mathrm{C}$ during the on-off cycles of the SoC. The on-off cycles last approximately $1 \mathrm{~min}$, which is much longer than the response time of the IRC or thermocouples, so the system is able to resolve the time variation of the system performance.

The dashed lines in Figure 2 show the temperature trends of the aluminum shield recorded during another experiment. In this experiment, four thermocouples were attached to the aluminum shield as indicated in the figure, with a spacing of $15 \mathrm{~mm}$. The tablet operation procedure was carried out again, and the temperature evolution was registered during $12 \mathrm{~min}$ of operation. The shield temperatures at different locations present a similar behavior in terms of trend and magnitude. As expected, $T_{1}$ and $T_{2}$ are the highest because they are located closest to the SoC, and all the temperatures remain below $60{ }^{\circ} \mathrm{C}$. The air gap between the electronic components and the aluminum shield provides enough insulation to keep the aluminum shield at a constant temperature of approximately $55^{\circ} \mathrm{C}$ on average. The current heat management strategy of this tablet allows the surface temperature at the back cover to be much lower than the hot spot located on the SoC. On the other hand, the heat generated by the electronic components is not dissipated effectively, which results in higher hot spot temperatures, thus compromising the life of the electrical components and reducing the performance of the tablet.

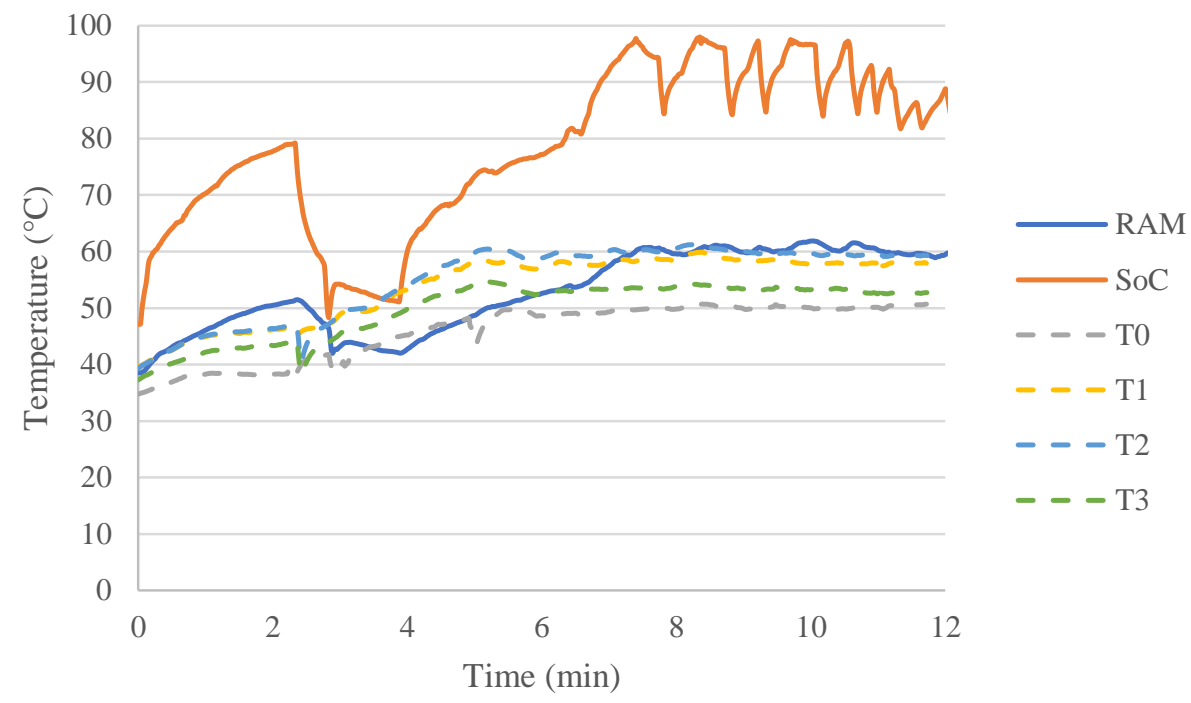

Figure 2. Temperature trends of the RAM and the SoC during 12 min of operation. 
(a)

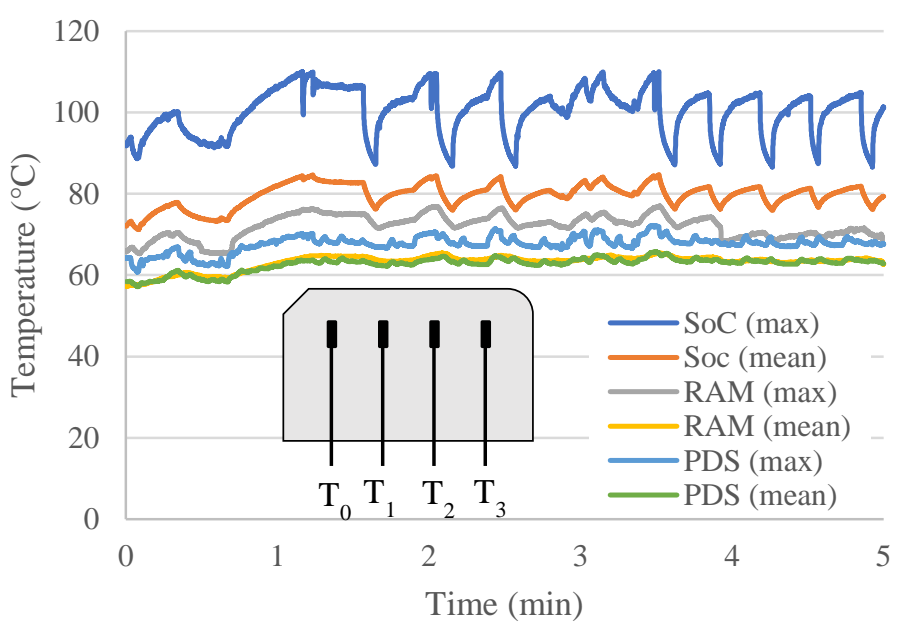

(b)

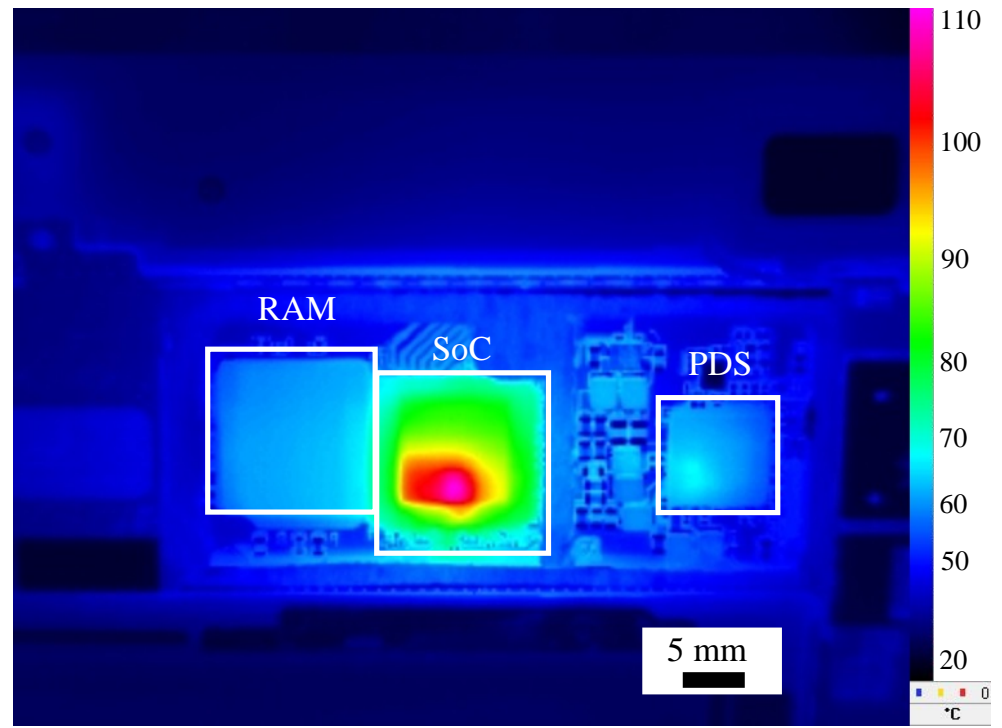

Figure 3. (a) Maximum and average temperature trends of the tablet main components recorded with the IRC and (b) thermal image of the tablet main components at maximum temperature operation.

Figure 3a presents the maximum and average temperature trends for each component during 5 min of operation. The temperature values were taken from the selected groups of pixels indicated in Figure $3 \mathrm{~b}$. Clearly, the hottest spot occurs in a specific location of the SoC at a maximum temperature of around $110^{\circ} \mathrm{C}$. This temperature is higher than that measured with the thermocouples (Figure 2). The IRC camera allows a precise location of the maximum temperature in the SoC, which in this case is located in a very specific and small area. The thermocouple was located at the center of the SoC occupying a zone affected by a temperature gradient. The temperature field at a specific frame is shown in Figure 3b. It gives a clear picture of the temperature distribution of the tablet electronic components. 


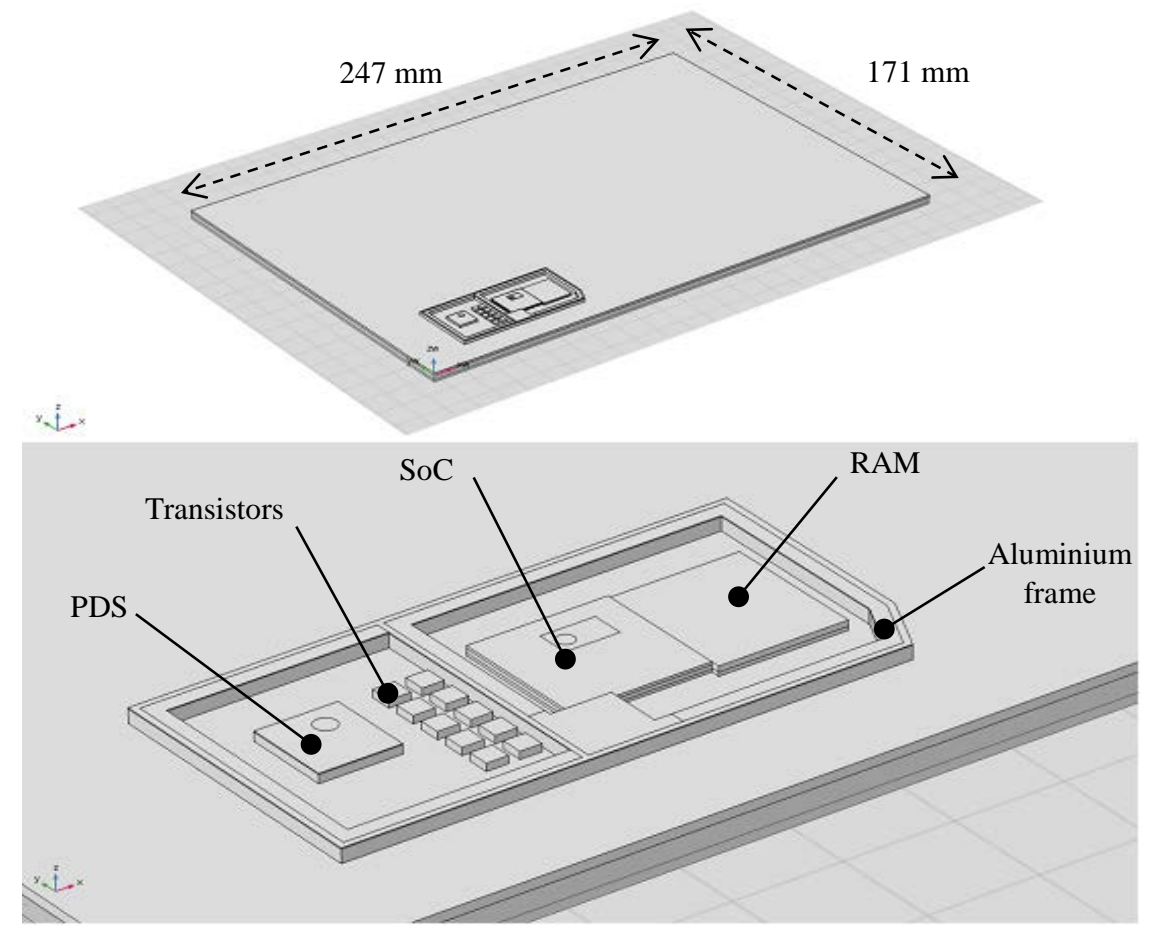

Figure 4. A CAD representation of the modeled tablet components.

Table 1. Dimensions of the tablet main electronic components

\begin{tabular}{cccc}
\hline \hline \multirow{2}{*}{ Component } & \multicolumn{3}{c}{ Dimensions (mm) } \\
\cline { 2 - 4 } & Length, $\boldsymbol{x}$-direction & Width, y-direction & Thickness, z-direction \\
\hline RAM & 11.8 & 13.3 & 1.0 \\
SoC & 12.8 & 12.7 & 1.0 \\
PDS & 7.5 & 8.0 & 1.0 \\
Transistors & 2.0 & 2.0 & 0.8 \\
Aluminum frame & 54.0 & 26.0 & 1.5 \\
\hline \hline
\end{tabular}

\subsection{Thermal Modelling of the Main Electronic Components}

Once the thermal behavior of the tablet has been evaluated, a numerical analysis was carried out using the Finite Element Method through the commercial simulation software COMSOL Multiphysics [35]. Two 3D steady-state models were developed: one model describes the thermal behavior of the main components without the aluminum shield, and the other model takes into account the aluminum shield as well.. Heat conduction and generation in the battery and the rest of the peripheral components was neglected because the IRC showed that their temperatures remain very close to ambient temperature. The dimensions of all relevant parts were measured by means of a digital caliber with a resolution of $1 \times 10^{-4} \mathrm{~m}$. Figure 4 presents a simplified schematic of the components that were modeled. It was assumed that the relevant electronic components lay on a rectangular structure that represents the tablet (see Figure 4). This rectangular structure has been modeled as three different material layers: FR4 (to simulate the circuit board), air (to simulate all the contact resistances and the existing air gaps between the electronic components), and glass (to simulate the screen). These structural layers have a thickness equal to $1 \mathrm{~mm}$ (FR4), $2 \mathrm{~mm}$ (air) and 1mm (glass). On top of this structure, the aluminum frame, SoC, RAM, PDS, and 10 transistors were modeled according to the dimensions reported in Table 1. The aluminum shield sits on top of the aluminum frame and has dimensions of $54 \times 26 \times 1.5 \mathrm{~mm}$. The chips were modeled as a combination of two acrylic plastic external layers and an internal silicon layer because, in most integrated chips, the semiconductor material is silicon and the mounting package is a polymer. The volumetric power generation was assigned to the silicon. It can also be seen that the SoC presents two subdomains: a small rectangle and a small circle. This has been done in order to reproduce as close as possible the shape of the hotspots measured by the IRC. The same technique was applied to the PDS. 
Table 2. Material properties for the thermal model

\begin{tabular}{cccc}
\hline \hline Material & $\boldsymbol{c}_{\boldsymbol{p}}(\mathbf{J} / \mathbf{k g K})$ & $\boldsymbol{\rho} \mathbf{( \mathbf { k g } / \mathbf { m } ^ { \mathbf { 3 } } )}$ & $\boldsymbol{k}(\mathbf{W} / \mathbf{m K})$ \\
\hline FR4 & 1396 & 1900 & 0.3 \\
Aluminum & 900 & 2700 & 238 \\
Acrylic Plastic/ Epoxy & 1470 & 1190 & 0.52 \\
Silicon & 700 & 2329 & 130 \\
Glass & 703 & 2203 & 1.38 \\
\hline \hline
\end{tabular}

Table 2 reports the specific heat, $c_{p}$, density, $\rho$, and thermal conductivity, $k$, of the materials used in the modeling. The air properties were calculated as a function of temperature using COMSOL's material library. The steady-state heat transfer is modeled using the energy conservation equation assuming no mass transfer or radiation:

$$
\rho c_{p} \nabla T-\nabla(k \nabla T)=Q_{v}-A_{w} q_{0}
$$

where $Q_{v}$ is the volumetric heat generation, $A_{w}$ is the wetted convective surface area, and $q_{0}$ is the heat flux from the surface to the air. The convective heat transfer between the surfaces (top of the electronic components and top the shield) and the air is described by the following equation:

$$
q_{0}=h\left(T-T_{\text {ext }}\right)
$$

where $h$ is the convective heat transfer coefficient and $T_{\text {ext }}$ is the ambient temperature. A constant value of $h$ was assumed for this work. Typical values of free convection of gases range from 2 to $25 \mathrm{~W} / \mathrm{m}^{2} \mathrm{~K}$ [36] and values of $10 \mathrm{~W} / \mathrm{m}^{2} \mathrm{~K}$ are recommended as a rule-of-thumb in the design of natural convection heat sinks [37]. For this reason, $h$ values of 4,8 , and $16 \mathrm{~W} / \mathrm{m}^{2} \mathrm{~K}$ were considered. A constant value of $T_{\text {ext }}$ of $293.15 \mathrm{~K}$ was assumed.

A modeling study was carried out in order to estimate heat generated from the electronic components. According to the tablet datasheet, the battery has a capacity, $C$, of 7 Ah and the tablet operates at a voltage, $V_{o p}$, of $3.8 \mathrm{~V}$. Assuming a $6 \mathrm{~h}$ operation period, $\tau$, to discharge completely the battery, the average current coming out of the battery, $I$, can be estimated as:

$$
I=C / \tau=7 A h / 6 h=1.17 A
$$

Therefore, the mean electric power supplied by the battery, $P$, is $4.45 \mathrm{~W}$. It was assumed that the display consumes 2.6 W. This assumption is based on some tests and comparison between 10-inch screen tablets [38].

The iterative process presented in the Appendix was used to determine the distribution of the energy consumption in the rest of the components. It was also used to determine the location and shape of the SoC and PDS subdomains that correspond to the hot spots.

The volumetric heat generation was treated as Joule heating in order to obtain the thermal power for the tablet components. The final power distribution is summarized in Table 3, and it can be seen that a significant part of the power was assigned to the aluminum frame surrounding the SoC, RAM, and PDS. The heat is transferred from the three main components to the circuit board. Then, a certain amount of heat is transferred from the circuit board to the screen, while the rest is transferred to the aluminum frame that is directly installed on the circuit board, as shown in Figure 1b.

The mesh for all the domains consisted of tetrahedral elements whose size ranged between $1 \times 10^{-6} \mathrm{~m}$ and $5 \times 10^{-3} \mathrm{~m}$. Other sizing parameters were a maximum element growth rate of 1.4 , curvature factor of 0.4 , and resolution of narrow regions of 0.7 . The mesh is much finer in the interfaces between the different domains as well as in the hot spot and is coarser in other domains. 
Table 3. Power distribution in the tablet main components

\begin{tabular}{cc}
\hline \hline Component & Power consumption (W) \\
\hline Screen & 2.60 \\
SoC & 0.84 \\
RAM & 0.14 \\
PDS & 0.11 \\
Transistors & 0.12 \\
Aluminum frame & 0.64 \\
\hline \hline
\end{tabular}

Figure 5 presents a comparison of the simulated and experimental temperature fields. It can be seen that a good agreement in terms of temperature distribution was achieved. To quantitatively assess the accuracy of the developed model, a comparison in terms of maximum and average temperatures in different domains is reported in Table 4 . The average and maximum temperatures deviate below $3 \mathrm{~K}$ in all domains except for the aluminum, where a deviation of $4.8 \mathrm{~K}$ in the maximum temperature and a deviation of $6.7 \mathrm{~K}$ in the average temperature occur. The agreement between experiment and simulation was generally good. The largest discrepancy between the two occurred in the aluminum frame. The disagreement may be because there may be additional heat dissipated by the screen or related components mounted on the other side of the aluminum frame or because the actual free convection coefficient was lower than assumed. The developed COMSOL model was used as a baseline to generate the enhanced heat sinks using topology optimization.

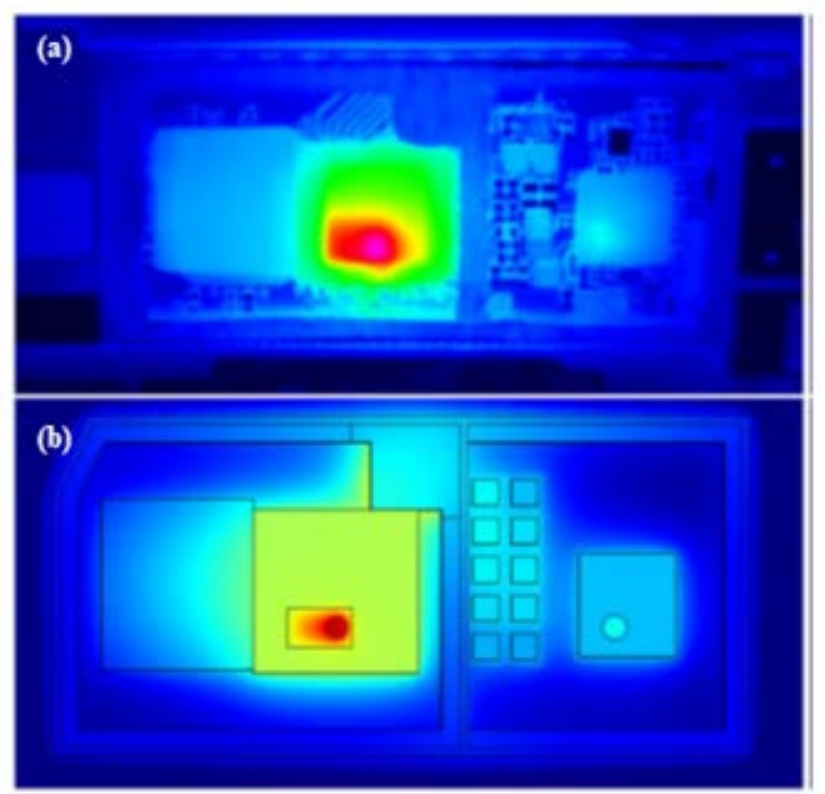

Figure 5. (a) Temperature field obtained with the IRC and (b) temperature field obtained from the COMSOL simulation.

Table 4. Experimental and simulated maximum and average temperatures in the tablet components

\begin{tabular}{ccccc}
\hline \hline \multirow{2}{*}{ Domain } & \multicolumn{2}{c}{ Maximum temperature } & \multicolumn{2}{c}{ Average temperature } \\
\cline { 2 - 4 } & $\operatorname{Exp}\left({ }^{\circ} \mathbf{C}\right)$ & $\operatorname{Sim}\left({ }^{\circ} \mathbf{C}\right)$ & $\operatorname{Exp}\left({ }^{\circ} \mathbf{C}\right)$ & $\operatorname{Sim}\left({ }^{\circ} \mathbf{C}\right)$ \\
\hline SoC & 108.8 & 110.0 & 85.8 & 83.0 \\
RAM & 75.0 & 76.0 & 65.0 & 64.3 \\
PDS & 72.0 & 73.5 & 65.6 & 65.8 \\
Aluminum & 74.8 & 70.0 & 60.7 & 54.0 \\
Transistors & 67.5 & 68.0 & 65.2 & 65.5 \\
\hline \hline
\end{tabular}




\section{Topology optimization design}

\subsection{Non-robust Formulation}

In this paper, the focus is set on the user experience from the standpoint of temperature of the tablet surfaces rather than component lifetime. The average temperature was deemed more suitable than, for example, the maximum temperature because hot spots in the design domain can be diffused across the back cover of the tablet. The overall temperature of the table was deemed more important than localized hot spots. Therefore, the optimization problem becomes:

$$
\operatorname{Min} f\left(T, \rho_{\text {design }}\right)=\frac{1}{A} \int T d \Omega
$$

subject to

$$
\begin{gathered}
0 \leq \rho_{\text {design }} \leq 1 \\
\frac{1}{V o l} \int \rho_{\text {design }} d \Omega \leq \varphi_{\text {max }} \\
\operatorname{res}\left(T, \rho_{\text {design }}\right)=0
\end{gathered}
$$

where $T$ and $\rho_{\text {design }}$ are the density and temperature of the material that is distributed within the domain volume, respectively, $A$ is the surface area of the entire tablet, and $\varphi_{\max }$ is the maximum volume fraction imposed as a volume inequality constraint. $\varphi_{\max }$ is the ratio of the volume of the material of higher conductivity to the total volume, $\mathrm{Vol}$, and res is the residual of the governing equations within the discretized system. $\rho_{\text {design }}$ is a continuous variable field that can take values between 0 and 1 , where 0 corresponds to an insulating material (air) and 1 corresponds to the high conductivity material (aluminum). Values between 0 and 1 do not have any physical meaning in the considered application and are thus avoided in the optimized designs.

Density filtering is used in order to obtain topology optimized designs with smooth boundaries between heat sink material and air domains. A density filter based on the solution of the Helmholz partial differential equation is used in this work because it produces mesh independent results and it is computationally efficient. Considering that the heat sink material is isotropic, the density filter can be defined as [39]:

$$
-r^{2} \nabla^{2} \tilde{\rho}+\tilde{\rho}=\rho_{\text {design }}
$$

where $\tilde{\rho}$ was the filtered density, and $r$ is the filter parameter. In this work, $r$ is set to 1.5 times the maximum mesh element size in the design domain. Density filtering inherently introduces a band of intermediate density values at the interface between heat sink material and air. To reduce the width of this intermediate density band at the interfaces, a smoothed heaviside projection was used. An expression based on the tanh function provides a computationally fast way to obtain the projection [40]

$$
\overline{\tilde{\rho}}=\frac{\tanh (\beta \eta)+\tanh (\beta(\tilde{\rho}-\eta))}{\tanh (\beta \eta)+\tanh (\beta(1-\eta))}
$$

where $\overline{\tilde{\rho}}$ is the projected density field, $\eta$ is the projection threshold, usually 0.5 , and $\beta$ defines the steepness of the projection. The solid isotropic material with penalization (SIMP) method was used to obtain the effective thermal conductivity of the material in the regions when the design density is different from 0 or 1 , where $k_{\text {eff }}$ is defined as: 


$$
k_{e f f}=k_{\text {air }}+\left(k_{A l}-k_{\text {air }}\right) \overline{\tilde{\rho}}^{p}
$$

where $p$ is the penalization exponent. A value of $p$ greater than 1 penalizes intermediate design densities and can be used in connection with a volume constraint for achieving $0 / 1$ designs without large areas of intermediate densities.

\subsection{Robust formulation}

The filtering-projecting approach does not ensure a precise control over the minimum length scale. One of the most typical problems is the so-called "critical one node connection": only a single mesh node connects two different entities. The main idea behind the robust approach is to obtain three different density profiles, namely eroded $(e)$, intermediate $(i)$, and dilated $(d)$, and then optimize the problem for the worst case. These density profiles can be obtained by projecting to the original filtered equation in three different ways [40]:

$$
\begin{gathered}
\overline{\tilde{\rho}}_{i}=\frac{\tanh (\beta \eta)+\tanh (\beta(\tilde{\rho}-\eta))}{\tanh (\beta \eta)+\tanh (\beta(1-\eta))} \\
\overline{\tilde{\rho}}_{e}=\frac{\tanh (\beta(1-t))+\tanh (\beta(\tilde{\rho}-(1-t)))}{\tanh (\beta(1-t))+\tanh (\beta(1-(1-t)))} \\
\overline{\tilde{\rho}}_{d}=\frac{\tanh (\beta \eta)+\tanh (\beta(\tilde{\rho}-t))}{\tanh (\beta \eta)+\tanh (\beta(1-t))}
\end{gathered}
$$

Eq. (11) is the same as in the non-robust approach but in this case, it is referred to as intermediate. In Eq. (12-13) the parameter $t$ (threshold) is taken into account, which shifts the position of the ramp in the projection process. This approach combined with the filtering implies that for high values of $\beta$, the density of the central element is set to 1 if there is at least one element in the neighborhood which has a density greater than 0 . The opposite happens to the eroded density. Therefore, the core problem can be written as:

Given

$$
f\left(T\left(\rho_{\text {design }}\right)\right)=\frac{1}{A} \int T d \Omega
$$

minimize

$$
\max \left[\left(f\left(T, \rho_{e, \text { design }}\right)\right),\left(f\left(T, \rho_{i, \text { design }}\right)\right),\left(f\left(T, \rho_{\text {d,design }}\right)\right)\right]
$$

subject to

$$
\begin{gathered}
0 \leq \rho_{\text {design }} \leq 1 \\
r\left(T, \rho_{\text {design }}\right)=0 \\
\frac{1}{V o l} \int \overline{\tilde{\rho}}_{d} d \Omega \leq \varphi_{\max }
\end{gathered}
$$

Note that in this version of the algorithm the dilated density is used for the volume constraint (Eq. 18). Moreover, note that due to the physics of the specific problem that is treated, it is known a priori that the eroded design will lead to the highest heat sink temperature because this heat sink has less surface area than the heat sinks of the dilated and intermediate design. This knowledge can be used to avoid the minimax formulation (Eq. 15) for which the state problem would need to be solved three times. Instead, it is sufficient to only solve the state problem once using the eroded density for the thermal conductivity calculation:

$$
k_{e f f}=k_{a i r}+\left(k_{A l}-k_{a i r}\right) \overline{\tilde{\rho}}_{e}^{p}
$$




\subsection{Computational set-up}

The topology optimization design has been treated as a 2D problem because the heat sink should lie directly over the electronic components and there is very limited space between those and the tablet back cover. The concept is to directly install the optimized design on the aluminum shield in order to keep good contact between the two parts and to avoid air gaps that increase the thermal resistance. An L-shape domain was chosen to avoid any heat flux toward the battery and to guarantee a good escape path for the heat (see Figure 6). The green region represents the domain reserved for the material distribution, i.e. the design domain, while the yellow region corresponds to the aluminum shield. The area occupied by the heat sink is determined by the volume constraint.

A constant heat flux of $309 \mathrm{~W} / \mathrm{m}^{2}$ entering from the bottom was assumed because the optimized design will be directly installed on the aluminum shield and in order to simplify the topology optimization problem. This value is derived from the preliminary thermal modeling (section 2.3) and it corresponds to the specific heat flux on the surface of the aluminum shield calculated by the steady-state COMSOL model. The heat source was applied to the yellow domain in Figure 6. A constant convection heat transfer coefficient was applied to the material distribution domain. Table 5 presents the parameter values used to solve both the non-robust and the robust topology optimization problems. It can be seen that a range of volume constraint values was used.

It was necessary to introduce an extra Dirichlet boundary condition in which the density of the battery zone boundaries is set to zero. This was done in order to avoid distributing conducting material close to the battery, i.e. to enforce a small air gap between the heat sink and the battery.

COMSOL's optimization module is used to conduct the optimization and the Globally Convergent version of the Method of Moving Asymptotes (GCMMA) [41] is used as the optimization method. A continuation approach [42], [43] is applied to the projection steepness parameter, $\beta$, in order to have a more regularized and convex optimization problem in the beginning of the optimization and to subsequently gradually increase the projection steepness to decrease the width of the intermediate density band between the air and heat sink material. The following values are used: $\beta=\{1,3,5,7,9,11\}$.

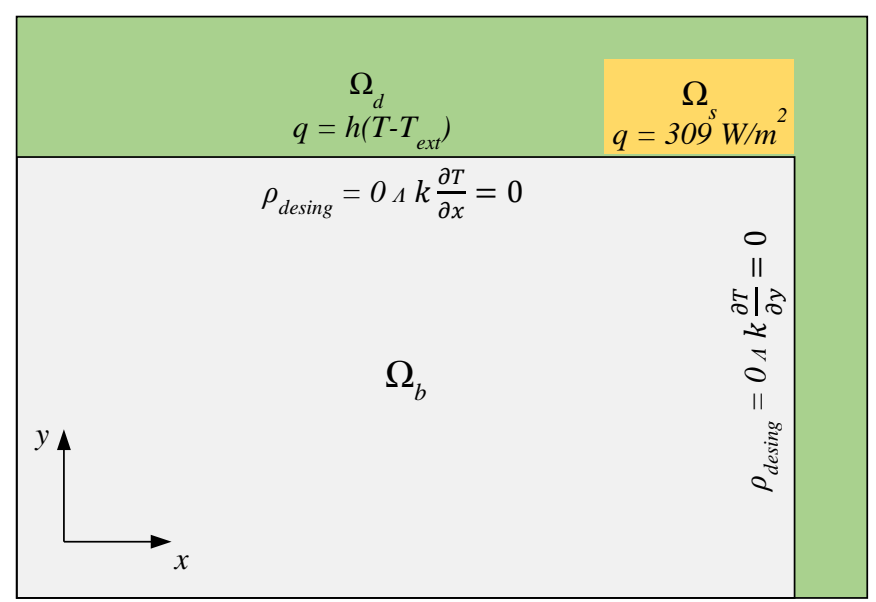

Figure 6. Depiction of the 2D tablet topology optimization model. Green corresponds to the design domain where heat sink material can be placed during the optimization $\left(\Omega_{d}\right)$, yellow corresponds to the non-optimizable aluminum shield below which the heat generation occurs $\left(\Omega_{s}\right)$, and grey indicates the further non-optimizable area (mainly the volume occupied by the battery) $\left(\Omega_{b}\right)$.

Table 5. Parameter values for the topology optimization problems

\begin{tabular}{cc}
\hline \hline \# of mesh elements & 39962 \\
Min/Max mesh element size $(\mathrm{m})$ & $3 \cdot 10^{-6} / 10^{-3}$ \\
Max number of iterations & 100 \\
$p$ & 3 \\
Starting value for $\rho_{\text {design }}$ & 0.5 \\
$\eta$ & 0.5 \\
$\varphi_{\max }$ & $0.1-0.2-0.3$ \\
$t^{*}$ & 0.1 \\
Tolerance & $1 \mathrm{e}-6$ \\
\hline \hline
\end{tabular}




\section{Results}

\subsection{Topology optimization designs}

Figure 7 shows the solution of the topology optimization problem for the non-robust case for a maximum aluminum volume fraction in the design domain, $\varphi_{\max }$, of $10 \%, 20 \%$, and $30 \%$ when $h$ is set to $8 \mathrm{~W} / \mathrm{m}^{2} \mathrm{~K}$. The red zone corresponds to the region where the material, aluminum, is distributed. In this zone, $\rho_{\text {design }}=1$.The blue zone corresponds to the region without material. In this zone, $\rho_{\text {design }}=0$. It can be seen that the topology optimized heat sinks are not very sharp; there is a noticeable zone with intermediate densities between the red and the blue zones. The shape of the three different topology optimized heat sinks is very similar. Nevertheless, as expected, the greater $\varphi_{\max }$, the larger the heat sink overall size (the number of branches increase) and the lower the average temperature.

Figure 8 presents the dilated, eroded and intermediate final solution of the topology optimization problem for the robust case with a maximum aluminum volume fraction in the design domain of $30 \%$. It is worth noting the nearly complete absence of zones with intermediate densities in the intermediate formulation. These heat sinks should be easier to manufacture than the non-robust heat sinks because of the more defined shape.

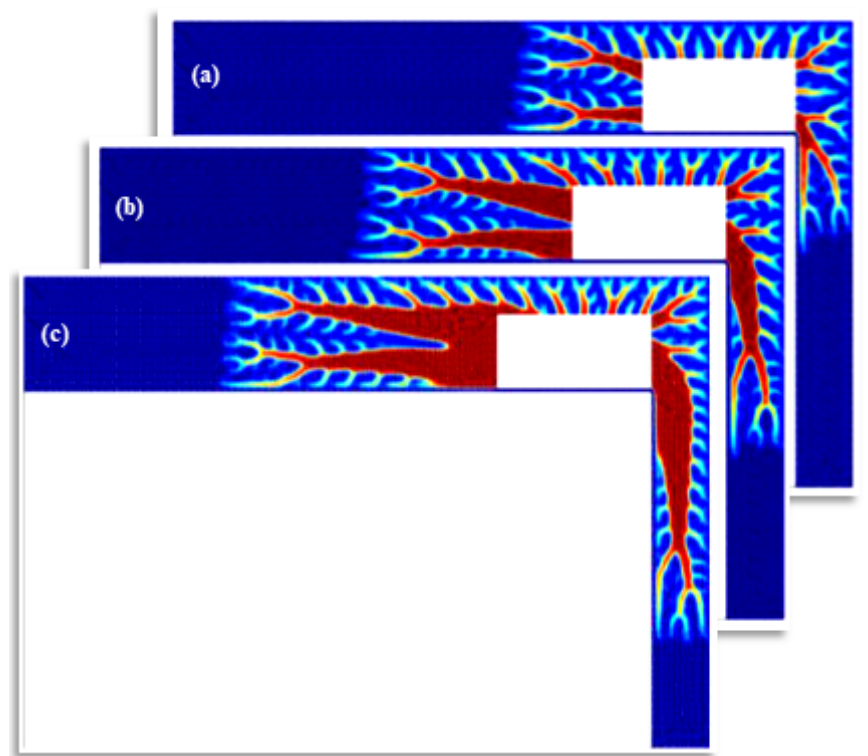

Figure 7. Topology optimization results for the non-robust case (a) $\varphi_{\max }=0.1$ (b) $\varphi_{\max }=0.2$ (c) $\varphi_{\max }=0.3$. Red corresponds to heat sink material (aluminum) and blue to void (air).

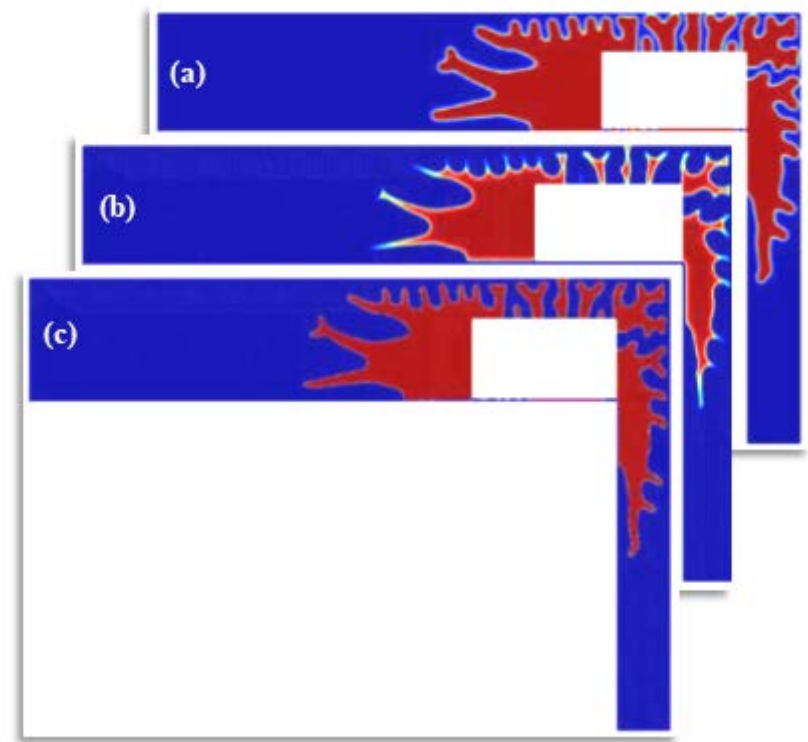

Figure 8. Topology optimization results for the robust case with $\varphi_{\max }=0.3$ (a) dilated (b) eroded (c). Red corresponds to heat sink material (aluminum) and blue to void (air). 
The influence of $h$ on the topology optimization results can be seen in Figure 9, where the resulting designs for values of 4,8 , and $16 \mathrm{~W} / \mathrm{m}^{2} \mathrm{~K}$ are presented. The basic shape and geometry of all the heat sink designs are similar: two main horizontal aluminum sections branch from the left side of the aluminum shield, one main vertical branch forms on the right side of the aluminum shield, and there are numerous secondary branches. The lower the value of $h$, the longer and thinner the branches become as the optimization scheme starts to favor increased convection surface to improved conduction cross section.

Figure 10 shows the effect of the mesh resolution and filter parameter on the topology optimization results, i.e. mesh size in the design domain and filter parameter are similarly decreased such that their ratio is kept constant. It can be seen that the final value of the average domain temperature is nearly the same for all cases. With decreasing element size and decreasing filter parameter, finer structures with more sub-branches are obtained even though the main shape remains similar. However, these very fine features would be more difficult to manufacture. Finally, the thickness of the intermediate density zone reduces with a finer mesh.

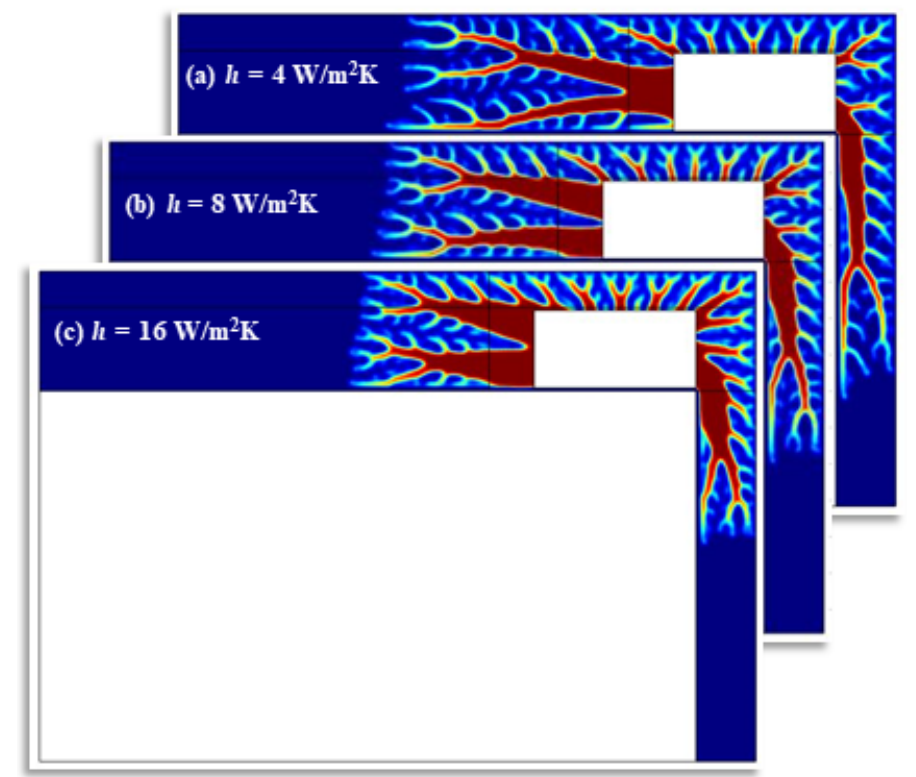

Figure 9. Effect of $h$ on the topology optimization results for the non-robust case with $\varphi_{\max }=0.2$ (a) $h=4 \mathrm{~W} / \mathrm{m}^{2} \mathrm{~K}$ (b) $h=8 \mathrm{~W} / \mathrm{m}^{2} \mathrm{~K}$ (c) $h=16 \mathrm{~W} / \mathrm{m}^{2} \mathrm{~K}$.

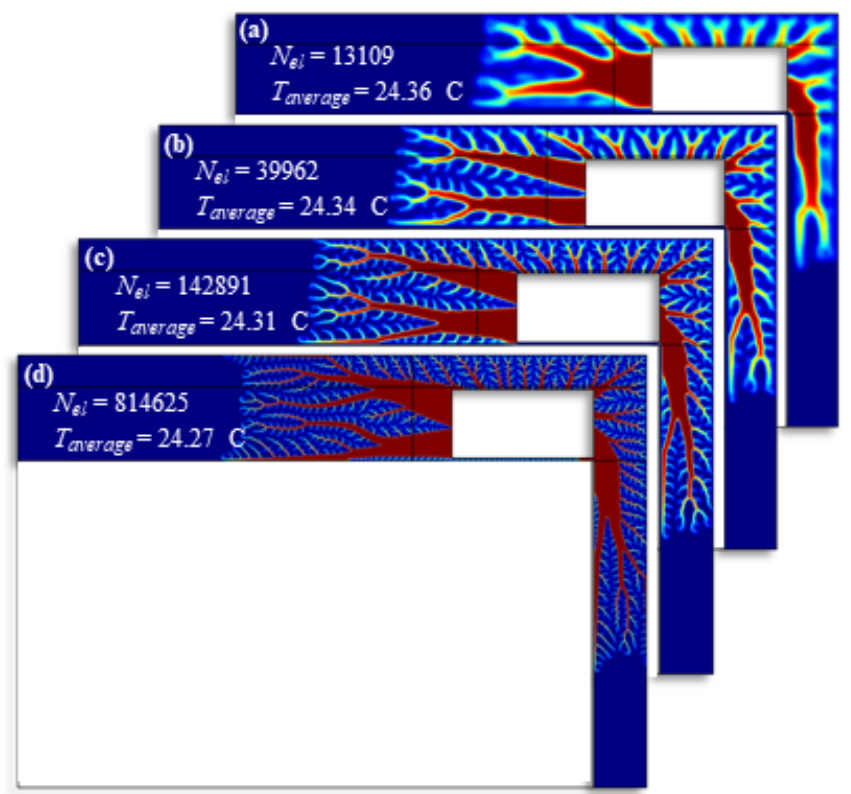

Figure 10. Effect of mesh resolution on the topology optimization results for the non-robust case with $\varphi_{\max }=0.2$ (a) 13109 elements (b) 39962 elements (c) 142891 elements (d) 814625 elements. 


\subsection{Numerical comparison}

The performance of the optimized design was studied by means of 3D simulations. A baseline L-shaped heat sink is also studied in order to compare the topology optimized heat sinks with a traditional heat sink. For each volume constraint, the area of the baseline heat sink is nearly the same as the area of the robust topology optimized heat sink. The area of the non-robust heat sink is slightly larger than the robust case for the same volume constraint values due to the resulting gray-zones.

Three heat sink options (baseline, robust, and non-robust) were compared by simulating their thermal behavior in conjunction with the rest of the tablet components. Two modeling approaches were used. In the first approach (constant $h$ ) a convective heat transfer coefficient of $8 \mathrm{~W} / \mathrm{m}^{2} \mathrm{~K}$ was set on all surfaces, including the heat sinks. In the second approach (airbox) all the domains are surrounded by an air volume that allows the model to explicitly capture the natural convection effects around the tablet when it is oriented at $25^{\circ}$. For the experimental tests, the heat sinks were mounted on top of the aluminum shield using thermal paste. For this reason, the influence of the thermal paste was also included in the 3D numerical model by introducing a $0.1 \mathrm{~mm}$ layer $(\mathrm{k}=5 \mathrm{~W} / \mathrm{m}-\mathrm{K})$ between the shield and the heat sinks. Table 6 summarizes the results in terms of average and maximum temperatures in the regions of the heat sinks that are in direct contact with the aluminum shield. In all cases, the baseline heat sink exhibits the worst performance, as it results in the highest temperatures. As $\varphi$ increases, the resulting temperatures in all cases decrease because there is more material, and therefore, a greater surface area available to transfer the heat. However, this effect is much more noticeable when $\varphi$ varies from 0.1 to 0.2 , than when $\varphi$ varies from 0.2 to 0.3 . In other words, the heat sink performance exhibits asymptotic performance as $\varphi$ increases.

The influence of the tablet position was also studied by means using the 'airbox' 3D model. Table 7 reports the average and maximum temperatures of the heat sinks with a volume constraint of 0.2 at an orientation of $25^{\circ}, 45^{\circ}$, and $65^{\circ}$. As the angle with respect to the vertical increases, the temperature of the heat sinks also increases due to reduced natural convection. In this case, the benefit of the topology optimized heat sinks becomes more evident. When the angle is $65^{\circ}$ the temperature difference between the non-robust heat sink and the baseline heat sink is approximately $8.3^{\circ} \mathrm{C}$.

Table 6. Heat sinks simulation results: comparison of the average and maximum temperatures of the heat sink area corresponding to the projection of the aluminum shield.

\begin{tabular}{|c|c|c|c|c|c|c|c|}
\hline & & \multicolumn{3}{|c|}{ Constant $h$} & \multicolumn{3}{|c|}{ Airbox } \\
\hline & & Baseline & Robust & Non-robust & Baseline & Robust & Non-robust \\
\hline \multirow{2}{*}{$\begin{array}{l}\dddot{m} \\
\ddot{\theta} \\
0\end{array}$} & $\begin{array}{c}\mathrm{T}_{\text {average }} \\
\left({ }^{\circ} \mathrm{C}\right)\end{array}$ & 38.39 & 38.17 & 37.62 & 42.89 & 39.70 & 38.31 \\
\hline & $\begin{array}{l}\mathrm{T}_{\max } \\
\left({ }^{\circ} \mathrm{C}\right)\end{array}$ & 39.60 & 39.95 & 39.49 & 44.13 & 41.51 & 40.20 \\
\hline \multirow{2}{*}{$\underset{\theta}{\stackrel{N}{\theta}}$} & $\begin{array}{c}\mathrm{T}_{\text {average }} \\
\left({ }^{\circ} \mathrm{C}\right)\end{array}$ & 43.28 & 42.46 & 41.26 & 47.66 & 43.51 & 41.32 \\
\hline & $\begin{array}{l}\mathrm{T}_{\max } \\
\left({ }^{\circ} \mathrm{C}\right)\end{array}$ & 44.77 & 44.19 & 43.10 & 49.17 & 45.27 & 43.20 \\
\hline \multirow{2}{*}{$\begin{array}{l}\ddot{\theta} \\
\text { II } \\
\theta\end{array}$} & $\begin{array}{c}\mathrm{T}_{\text {average }} \\
\left({ }^{\circ} \mathrm{C}\right)\end{array}$ & 49.98 & 48.93 & 47.40 & 54.78 & 49.83 & 46.85 \\
\hline & $\begin{array}{l}\mathrm{T}_{\max } \\
\left({ }^{\circ} \mathrm{C}\right)\end{array}$ & 51.40 & 50.59 & 49.14 & 56.22 & 51.53 & 49.14 \\
\hline
\end{tabular}

Table 7. Heat sinks numerical comparison in terms of the average and maximum temperatures for different spatial orientations.

\begin{tabular}{|c|c|c|c|c|}
\hline & & \multicolumn{3}{|c|}{ Position } \\
\hline & & $25^{\circ}$ & $45^{\circ}$ & $65^{\circ}$ \\
\hline \multirow{2}{*}{ Baseline } & $\mathrm{T}_{\text {average }}\left({ }^{\circ} \mathrm{C}\right)$ & 49.5 & 50.6 & 53.0 \\
\hline & $\mathrm{T}_{\max }\left({ }^{\circ} \mathrm{C}\right)$ & 51.1 & 52.2 & 54.6 \\
\hline \multirow{2}{*}{ Robust } & $\mathrm{T}_{\text {average }}\left({ }^{\circ} \mathrm{C}\right)$ & 45.1 & 46.0 & 47.7 \\
\hline & $\mathrm{T}_{\max }\left({ }^{\circ} \mathrm{C}\right)$ & 46.8 & 47.7 & 49.5 \\
\hline \multirow{2}{*}{ Non-robust } & $\mathrm{T}_{\text {average }}\left({ }^{\circ} \mathrm{C}\right)$ & 42.7 & 43.4 & 44.7 \\
\hline & $\mathrm{T}_{\max }\left({ }^{\circ} \mathrm{C}\right)$ & 44.6 & 45.2 & 46.6 \\
\hline
\end{tabular}


The experimental tests described in the next section were carried out without the back plastic cover because it was not possible to install it after placing the heat sinks. This does not correspond to real-life conditions. Therefore, the 'airbox' 3D model was expanded in an additional simulation study by adding a $0.1 \mathrm{~mm}$ thermal paste domain on top of the heat sinks, and then by adding the back cover domain (considering a thickness of 1 $\mathrm{mm}$ and the properties of the acrylic plastic/epoxy showed in Table 2) in contact with the thermal paste domain. The maximum temperatures on the back cover with an orientation of $25^{\circ}$ were $47.2{ }^{\circ} \mathrm{C}, 38.3^{\circ} \mathrm{C}$, and $37.6^{\circ} \mathrm{C}$ for the baseline, robust, and non-robust heat sink, respectively. The large surface of the back cover helps to dissipate the heat transferred from heat sinks to the ambient. The more effective and better-distributed heat conduction of the topology optimized heat sinks, given their tree-like aluminum structures, allows reducing the hot spot in the back cover by approximately $9{ }^{\circ} \mathrm{C}$ with respect to the baseline heat sink.

\subsection{Experimental comparison of heat sinks}

Three heat sink designs corresponding to a volume constraint of 0.2 were manufactured (baseline, robust and non-robust) by laser cutting (Figure 11) aluminum plate. The heat sinks had nominally equal areas in order to give a meaningful comparison: $0.0044 \mathrm{~m}^{2}$ for the baseline heat sink, $0.0047 \mathrm{~m}^{2}$ for the robust heat sink, and $0.0054 \mathrm{~m}^{2}$ for the non-robust heat sink. It should be emphasized that the area used in the model for each heat sink is the same. The increase in area for the robust heat sink was relatively small, $6.8 \%$, but there was a larger increase during the production phase for the non-robust heat sink. We optimized for exactly the same surface area and the differences between topology optimized heat sinks and the baseline come from post-processing of the optimized designs into programs used to manufacture each heat sink. The material used was an aluminum 6061 sheet with a $0.5 \mathrm{~mm}$ thickness. The tests were performed with the heat sinks fixed to the aluminum shield by means of nylon screws. In addition, the heat sinks were covered with graphite paint for IRC measurements. Since the aluminum shield is not completely flat, thermal paste with thermal conductivity of $5 \mathrm{~W} / \mathrm{m}-\mathrm{K}$ was used to mount the heat sinks on the shield. This ensures a low thermal resistance at the contact surface because the thermal paste fills any gap between the two surfaces. The tablet position and operation procedure for these tests were the same as in the preliminary thermal analysis. For each test, the temperature images were registered for $5 \mathrm{~min}$ at a sampling rate of $25 \mathrm{~Hz}$. The zone used to estimate the maximum and average temperatures from the IRC imaging does not correspond to the complete projection of the aluminum shield surface. The areas occupied by the nylon screws were excluded because the average temperature would be much lower if the complete projection were used. A reduced region that excludes the screws is, therefore, a better representation of the zone of interest, and the same area is used for the three heat sinks. Several tests were carried out for each heat sink in order to evaluate their performance. Figure 12 shows the temperature distribution of the three heat sinks after around $5 \mathrm{~min}$ of testing, which was the time required to reach steady-state. The reduced region used for the analyses corresponds to the area within the dashed rectangle. The baseline heat sink presents the least uniform temperature distribution. In contrast, the topology optimized heat sinks achieve more uniform distribution, avoiding the occurrence of a hot spot and indicating better thermal performance. The experimental results confirm the model findings. However, it should be noted that the area of the non-robust heat sink was higher due to manufacturing processing.

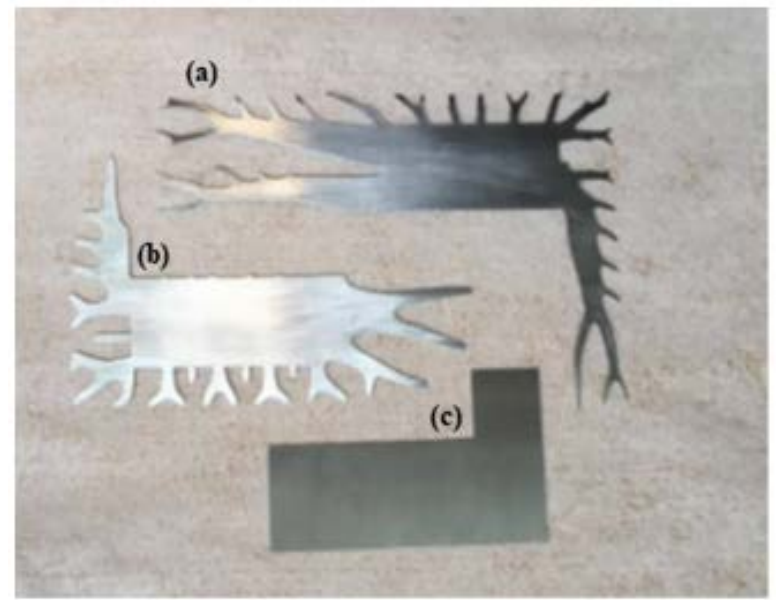

Figure 11. Manufactured heat sinks (a) non-robust (b) robust (c) baseline. 
(a)

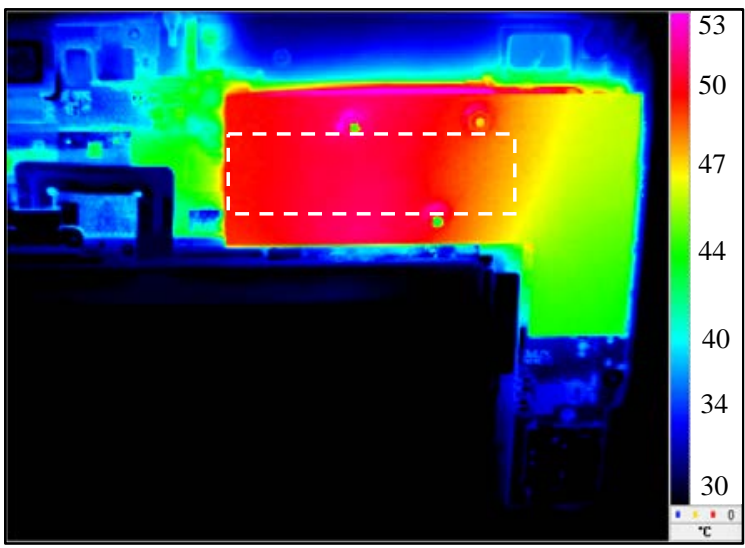

(b)

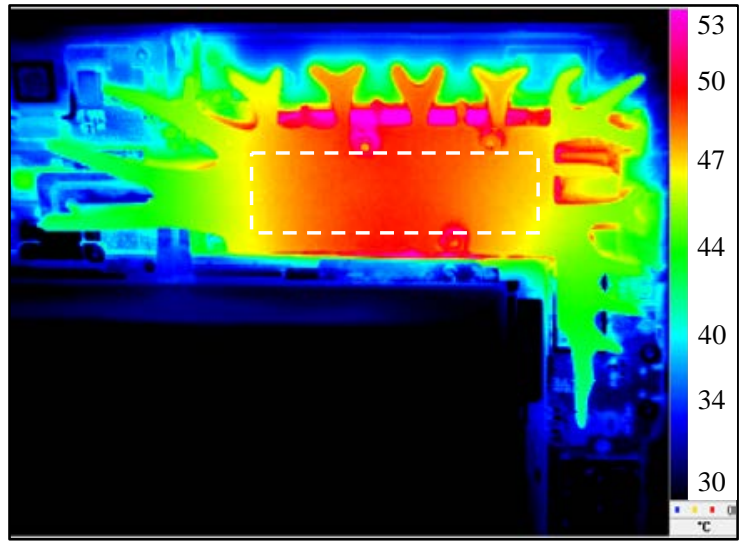

(c)

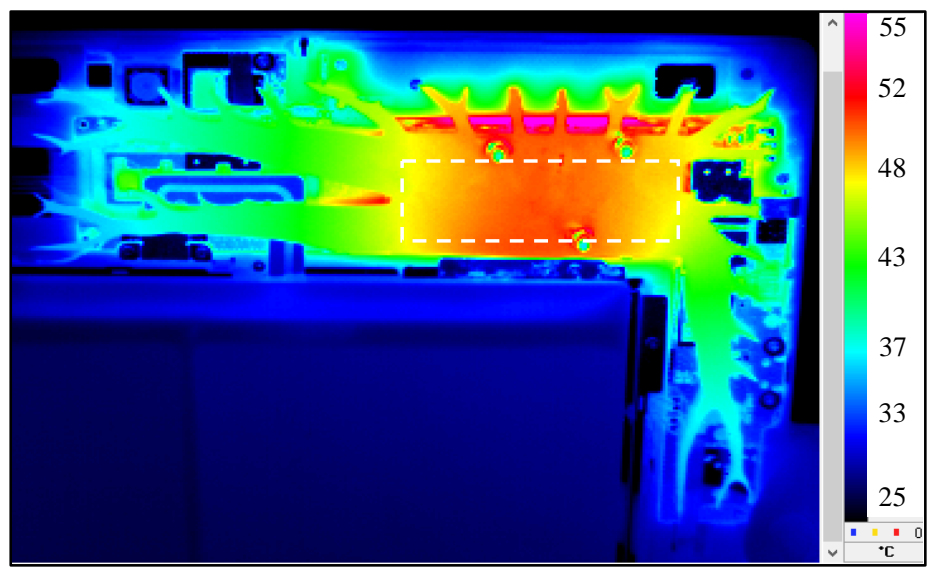

Figure 12. Temperature distribution after 5 min of testing (a) baseline heat sink, (b) robust heat sink, and (c) non-robust heat sink.

Table 8. Heat sinks experimental and numerical comparison in terms of average temperature

\begin{tabular}{ccc}
\hline \hline & \multicolumn{2}{c}{ Average temperature $\left({ }^{\circ} \mathbf{C}\right)$} \\
\cline { 2 - 3 } & Experimental & Numerical \\
\hline Baseline & 48.5 & 49.5 \\
Robust & 46.8 & 45.1 \\
Non-robust & 45.6 & 42.7 \\
\hline \hline
\end{tabular}

Table 8 reports the experimental average temperature of the heat sinks at an orientation of $25^{\circ}$ after 5 min. It also includes the numerical results using the 'airbox' 3D model in COMSOL for the same orientation. The experimental 
results are in agreement with the numerical comparison. Again, the best performing design is the non-robust followed by the robust design. Although the difference in performance between all the designs is not large, the non-robust heat sink is capable of reducing the average temperature by approximately $3^{\circ} \mathrm{C}$ with respect to the baseline heat sink.

\section{Conclusion}

This paper presented the design and testing of topology optimized heat sinks to enhance the thermal management of a commercial tablet. Firstly, the tablet thermal behavior during its operation was analyzed in order to build a thermal model of the tablet and estimate the values of the parameters and boundary conditions used for topology optimization. Modeling was also used to determine the location of the hot spots in the main components of the tablet. Topology optimization was performed in 2D due to the limited space between the aluminum shield and the tablet back cover. Two topology optimization approaches were used: the non-robust approach and the robust approach. In the robust approach, the topology optimized design has sharper with more defined edges since the resulting shape contained almost no zones with intermediate densities. This makes it more suitable for manufacturing. Several topology optimizations were carried out with three different values of the maximum heat sink material volume fraction in the design domain $(0.1,0.2$ and 0.3$)$. The optimized designs with a volume constraint of 0.2 were selected for fabrication and experimental testing because numerical studies indicated a good tradeoff between performance and the amount of material used for this volume constraint value.

Three heat sinks were fabricated in aluminum 6061: two topology optimized heat sinks (robust and nonrobust) and the baseline L-shaped heat sink, in order to compare the performance of topology optimized to a baseline heat sink. The heat sinks were compared numerically and experimentally, and both methods showed that the non-robust heat sink performs the best, with the lowest average temperature in the region corresponding to the aluminum shield projection. This reduction should improve the user experience of the tablet. The lowest performance (highest average temperature) heat sink was the baseline L-shaped. Furthermore, the thermal images obtained with the IRC showed that the temperature distribution is more uniform in the topology-optimized heat sinks. Finally, 3D simulations show that the hot spot in the back cover is approximately $9{ }^{\circ} \mathrm{C}$ lower when using the topology optimized heat sinks compared to the baseline heat sink. The lower and more uniform temperature is expected to improve the overall user experience and component lifetime of the tablet. 


\section{Appendix}

A flow diagram of the iterative to obtain the power distribution among the tablet electronic components is shown in Figure A.

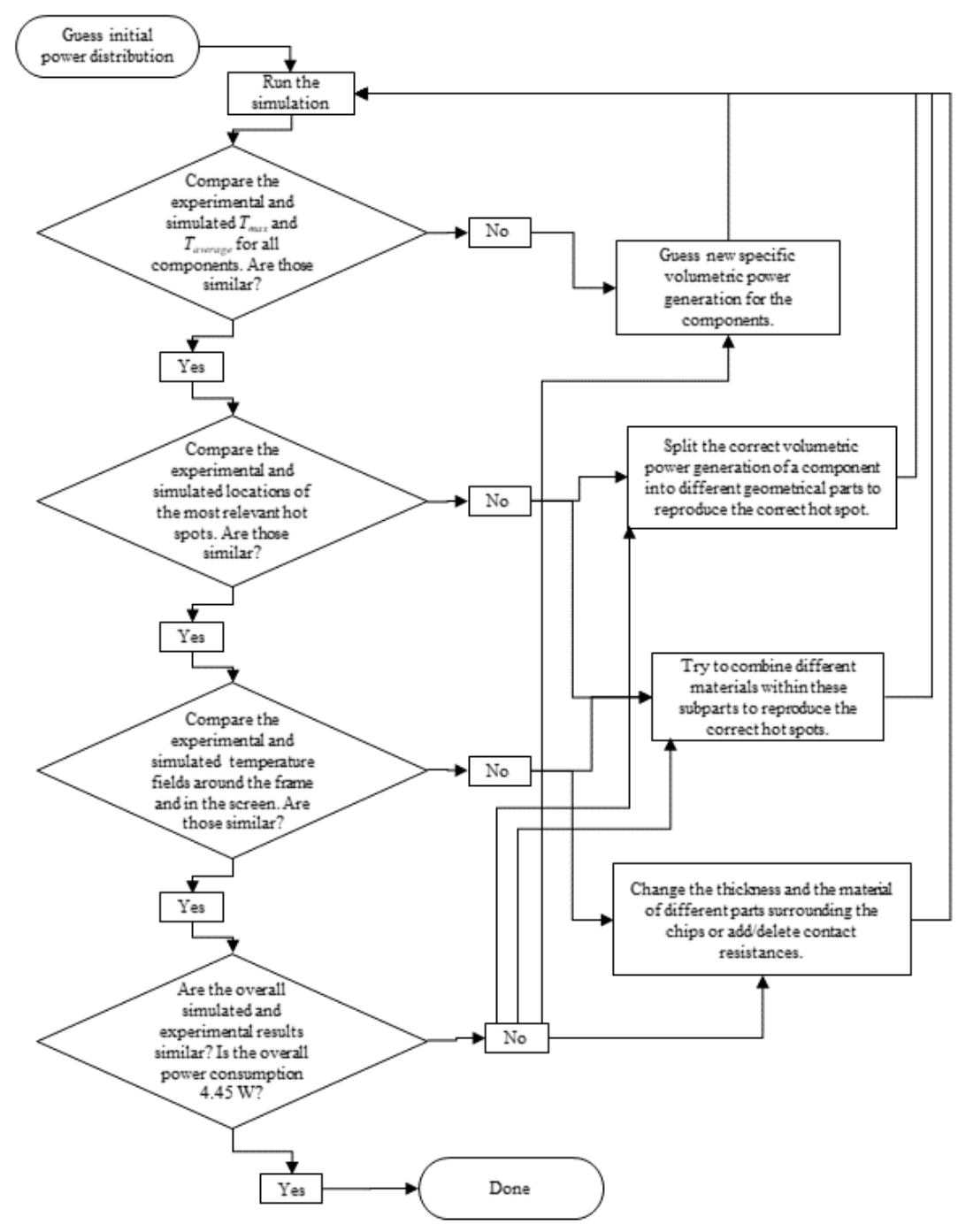

Figure A. Procedure to obtain the power distribution in the tablet electronic components.

\section{Acknowledgment}

This work was financed by the TopTEn project sponsored by the Sapere Aude Program of the 723 Danish Council for Independent Research (DFF - 4005-00320). Alessandro Manzo is grateful for a Tesi all'estero travel grant that helped support this work.

\section{References}

[1] K. Hirohata , K. Hisano, and M. Mukai, "Health-monitoring method of note PC for cooling performance degradation,” Microelectronics Reliability, vol. 51, pp. 255-262 , 2011. 
[2] S. V Garimella, T. Persoons, J. A. Weibel, and V. Gektin, “Electronics Thermal Management in Information and Communications Technologies: Challenges and Future Directions,” IEEE Trans. Components, Packag. Manuf. Technol., vol. 7, no. 8, pp. 1-15, 2016.

[3] M. K. Berhe, “Ergonomic Temperature Limits for Handheld Electronic Devices,” ASME 2007 InterPACK Conf. Vol. 2, pp. 1041-1047, 2007.

[4] G. Colangelo, E. Favale, M. Milanese, A. de Risi, and D. Laforgia, "Cooling of electronic devices: Nanofluids contribution,” Appl. Therm. Eng., vol. 127, pp. 421-435, 2017.

[5] J. R. Culham and Y. S. Muzychka, “Optimization of plate fin heat sinks using entropy generation minimization,” IEEE Trans. Components Packag. Technol., vol. 24, no. 2, pp. 159-165, 2001.

[6] Y. Ge, F. Shan, Z. Liu, and W. Liu, “Optimal structural design of a heat sink with laminar single phase flow using CFD based multi-objective genetic algorithm,” J. Heat Transfer, vol. 140, no. February, 2017.

[7] K. Park, P. K. Oh, and H. J. Lim, "The application of the CFD and Kriging method to an optimization of heat sink,” Int. J. Heat Mass Transf., vol. 49, no. 19-20, pp. 3439-3447, 2006.

[8] A. Bejan, “Constructal-theory network of conducting paths for cooling a heat generating volume,” Int. J. Heat Mass Transf., vol. 40, no. 4, pp. 799-816, 1997.

[9] R. Bornoff and J. Parry, “An additive design heatsink geometry topology identification and optimisation algorithm,” Annu. IEEE Semicond. Therm. Meas. Manag. Symp., vol. 2015-April, pp. 303-308, 2015.

[10] S. Qiu, Z. Xie, L. Chen, A. Yang, and J. Zhou, "Entropy generation analysis for convective heat transfer of nanofluids in tree-shaped network flowing channels,” Therm. Sci. Eng. Prog., vol. 5, no. December 2017, pp. 546-554, 2018.

[11] A. Lugarini, A. T. Franco, and M. R. Errera, "Design and Performance Evaluation of Constructal Microchannel Network Heatsinks,” J. Heat Transfer, vol. 140, no. 5, p. 052403, 2018.

[12] A. L. Razera, R. J. C. Fonseca, L. A. Isoldi, E. D. dos Santos, L. A. O. Rocha, and C. Biserni, “Constructal design of a semi-elliptical fin inserted in a lid-driven square cavity with mixed convection,” Int. J. Heat Mass Transf., vol. 126, pp. 81-94, 2018.

[13] M. P. Bendsøe and O. Sigmund, Topology Optimization - Theory, Methods and Applications. Springer Verlag, 2003.

[14] J. D. Deaton and R. V. Grandhi, “A survey of structural and multidisciplinary continuum topology optimization: Post 2000,” Struct. Multidiscip. Optim., vol. 49, no. 1, pp. 1-38, 2014.

[15] J. H. K. Haertel and G. F. Nellis, “A fully developed flow thermofluid model for topology optimization of 3Dprinted air-cooled heat exchangers,” Appl. Therm. Eng., vol. 119, pp. 10-24, 2017.

[16] Y. Joo, I. Lee, and S. J. Kim, “Topology optimization of heat sinks in natural convection considering the effect of shape-dependent heat transfer coefficient,” Int. J. Heat Mass Transf., vol. 109, pp. 123-133, 2017.

[17] A. Pizzolato, A. Sharma, K. Maute, A. Sciacovelli, and V. Verda, "Topology optimization for heat transfer enhancement in Latent Heat Thermal Energy Storage,” Int. J. Heat Mass Transf., vol. 113, pp. 875-888, 2017.

[18] V. Subramaniam, T. Dbouk, and J. L. Harion, “Topology optimization of conductive heat transfer devices: An experimental investigation,” Appl. Therm. Eng., vol. 131, pp. 390-411, 2018.

[19] J. H. K. Haertel, K. Engelbrecht, B. Lazarov, and O. Sigmund, “Topology Optimization of a Pseudo 3D Thermofluid Heat Sink Model,” Int. J. Heat Mass Transf., vol. 121C, pp. 1073-1088, 2018.

[20] O. Sigmund, "Design of multiphysics actuators using topology optimization - Part I: One material structures.,” Comput. Methods Appl. Mech. Eng., vol. 190, no. 49-50, pp. 6577-6604, 2001.

[21] S. H. Ahn and S. Cho, "Level set-based topological shape optimization of heat conduction problems considering design-dependent convection boundary,” Numer. Heat Transf. Part B Fundam., vol. 58, no. 5, pp. 304-322, 2010. 
[22] A. Iga, S. Nishiwaki, K. Izui, and M. Yoshimura, “Topology optimization for thermal conductors considering design-dependent effects, including heat conduction and convection,” Int. J. Heat Mass Transf., vol. 52, no. 1112, pp. 2721-2732, 2009.

[23] E. M. Dede, S. N. Joshi, and F. Zhou, “Topology Optimization, Additive Layer Manufacturing, and Experimental Testing of an Air-Cooled Heat Sink,” J. Mech. Des., vol. 137, no. 11, p. 111403, 2015.

[24] S. Soprani, J. H. K. Haertel, B. S. Lazarov, O. Sigmund, and K. Engelbrecht, “A design approach for integrating thermoelectric devices using topology optimization,” Appl. Energy, vol. 176, pp. 49-64, 2016.

[25] E. M. Dede, "Multiphysics topology optimization of heat transfer and fluid flow systems,” Proc. COMSOL Users Conf., 2009.

[26] G. H. Yoon, “Topological design of heat dissipating structure with forced convective heat transfer,” J. Mech. Sci. Technol., vol. 24, no. 6, pp. 1225-1233, 2010.

[27] E. M. Dede, “Optimization and Design of a Multipass Branching Microchannel Heat Sink for Electronics Cooling,” J. Electron. Packag., vol. 134, no. 4, p. 041001, 2012.

[28] A. A. Koga, E. C. C. Lopes, H. F. Villa Nova, C. R. de Lima, and E. C. N. Silva, "Development of heat sink device by using topology optimization,” Int. J. Heat Mass Transf., vol. 64, pp. 759-772, 2013.

[29] K. Yaji, T. Yamada, S. Kubo, K. Izui, and S. Nishiwaki, “A topology optimization method for a coupled thermalfluid problem using level set boundary expressions,” Int. J. Heat Mass Transf., vol. 81, pp. 878-888, 2015.

[30] S. B. Dilgen, C. B. Dilgen, D. R. Fuhrman, O. Sigmund, and B. S. Lazarov, "Density Based Topology Optimization of Turbulent Flow Heat Transfer,” Struct. Multidiscip. Optim., vol. 57, pp. 1905-1918, 2018.

[31] J. Alexandersen, N. Aage, C. S. Andreasen, and O. Sigmund, "Topology optimisation for natural convection problems,” Int. J. Numer. Methods Fluids, vol. 76, pp. 699-721, 2014.

[32] J. Alexandersen, O. Sigmund, and N. Aage, "Large scale three-dimensional topology optimisation of heat sinks cooled by natural convection,” Int. J. Heat Mass Transf., vol. 100, pp. 876-891, 2016.

[33] T. Dbouk, “A review about the engineering design of optimal heat transfer systems using topology optimization,” Appl. Therm. Eng., vol. 112, pp. 841-854, 2017.

[34] T. Lei, J. Alexandersen, B. S. Lazarov, F. Wang, J. H. K. Haertel, S. De Angelis, S. Sanna, O. Sigmund, K. Engelbrecht, "Investment casting and experimental testing of heat sinks designed by toloplogy optimization," Int. J. Heat Mass Transf., vol. 127B, pp. 396-412, 2018.

“COMSOL Multiphysics 5.3.” .

[36] Y. A. Cengel, Heat Transfer - A Practical Approach, 2nd Editio. Tata McGraw-Hil.

[37] C. J. M. Lasance, "Heat Sink Basics from an Industrial Point of View," in Thermal Management of LED Applications: Volume 2 - Solid State Lighting Technology and Application, C. J. M. Lasance and A. Poppe, Eds. New York: Springer, 2014.

[38] R. M. Soneira, “Tablet Display Technology Shoot-Out.” [Online]. Available: http://www.displaymate.com/Tablet_ShootOut_2.htm. [Accessed: 15-Jan-2018].

[39] B. S. Lazarov and O. Sigmund, "Filters in topology optimization based onHelmholtz-type differential equations," Int. J. Numer. Methods Eng., vol. 86, pp. 765-781, 2011.

[40] F. Wang, B. S. Lazarov, and O. Sigmund, "On projection methods, convergence and robust formulations in topology optimization,” Struct. Multidiscip. Optim., vol. 43, no. 6, pp. 767-784, 2011.

[41] K. Svanberg, “A Class of Globally Convergent Optimization Methods Based on Conservative Convex Separable Approximations,” SIAM J. Optim., vol. 12, no. 2, pp. 555-573, 2002.

[42] O. Sigmund and J. Petersson, "Numerical instabilities in topology optimization: A survey on procedures dealing with checkerboards, mesh-dependencies and local minima,” Struct. Optim., vol. 16, no. 1, pp. 68-75, 1998. 
[43] M. Stolpe and K. Svanberg, "On the trajectories of penalization methods for topology optimization," Struct. Multidiscip. Optim., vol. 21, no. 2, pp. 128-139, 2001. 